\title{
O HOMICÍDIO DO GÊNERO FEMININO NO ESTADO CONTEMPORÂNEO
}

\section{BRASILEIRO}

\author{
Kelly de Souza Barbosa ${ }^{1}$ \\ Maria Cristina Vidotte Blanco Tárrega ${ }^{2}$
}

\section{RESUMO}

Tendo em vista os assassinatos praticados contra mulheres no Brasil por causa do gênero, foi promulgada a Lei 13.104/2015 que cria a qualificadora do feminicídio. Destarte, o objetivo geral deste trabalho foi investigar o feminicídio no Brasil e, transversalmente, as causas para a sua criação e suas principais características. Os métodos aplicados foram o dedutivo e descritivo, e a pesquisa bibliográfica e documental. Indubitável a importância de mudanças legislativas penais, todavia elas devem vir acompanhadas de resultados concretos, especialmente, em relação ao combate do feminicídio contra as brasileiras.

Palavras-chaves: Mulher; Violência; Gênero; Feminicídio; Brasil.

\section{THE HOMICIDE OF THE FEMININE GENDER IN THE BRAZILIAN CONTEMPORARY STATE}

\begin{abstract}
In view of the murders committed against women in Brazil due to gender, Law 13.104/2015 establishing the qualifier of feminicide was promulgated. Thus, the general objective of this work was to investigate feminicide in Brazil and transversally the causes for its creation and its main characteristics. The applied methods were the deductive and descriptive, and the bibliographical and documentary research. Undoubtedly the importance of legislative changes in criminal law, however, must be accompanied by concrete results, especially in relation to combating feminicide against Brazilian women.
\end{abstract}

Keywords: Woman; Violence; Genre; Feminicide; Brazil.

\section{INTRODUÇÃO}

Dada as transformações sociais, políticas e jurídicas ocorridas na sociedade brasileira, o Direito Penal também passou por reformas a fim de ser readequado à realidade, principalmente para robustecer a tutela dos bens jurídicos reiteradamente lesionados, seja por

\footnotetext{
${ }^{1}$ Mestranda em Direitos Coletivos e Cidadania pela Universidade de Ribeirão Preto (UNAERP/SP), bolsista CAPES/PROSUP. Especialista em Direito Processual Civil e Processo Cautelar pela Universidade Cândido Mendes. Bacharela em Direito pela Universidade do Estado de Minas Gerais (UEMG). Advogada.

${ }^{2}$ Mestre em Direito Civil e Doutora em Direito Empresarial pela PUC-SP, é professora titular da Universidade Federal de Goiás e no Programa de Mestrado da Universidade de Ribeirão Preto. Pesquisadora bolsista produtividade do $\mathrm{CNPq}$, fez estágio pós-doutoral na Universidade de Coimbra.
} 
causa da punição ineficaz ou pela insuficiência das medidas preventivas para coibirem a prática.

No que tange aos homicídios praticados contra mulheres em razão do gênero, seja decorrente da violência doméstica e/ou familiar ou do menosprezo à condição feminina, em 2015 foi promulgada a Lei $\mathrm{n}^{\circ} 13.104$ que cria uma nova qualificadora para o crime em comento, haja vista o número expressivo e corriqueiro de casos no país.

Tendo como objetivo geral a análise da recente qualificadora atribuída ao crime de homicídio, denominada de feminicídio, foram especificamente exploradas as causas para o robustecimento sancionador do Estado brasileiro contra os homicidas de mulheres e as principais características deste novel instituto penal.

Para tanto foi empregada a metodologia dedutiva e descritiva conjugada com a pesquisa bibliográfica, pautada em renomados doutrinadores nacionais em matéria de Direito Penal e em artigos científicos sobre o assunto.

Também foi utilizada a pesquisa documental, restrita aos documentos jurídicos (leis, códigos e jurisprudências) e aos dados estatísticos constantes no "Mapa da violência 2015: Homicídio de mulheres no Brasil”, elaborado por Julio Jacobo Waisekfisz.

O primeiro capítulo abordou as principais características legais e doutrinárias do crime de homicídio no Brasil, evoluindo o capítulo seguinte para análise das questões sociojurídicas que justificaram a necessidade da criação de uma qualificadora específica para a penalização do homicídio de mulheres realizados no contexto doméstico e/ou familiar ou por causa do gênero.

Conquanto verifiquem-se alguns avanços relacionados aos direitos das brasileiras, estas ainda suportam uma grande discriminação no cenário nacional, corroborada por uma sociedade machista e um Estado omisso no seu dever de tutelar os mais vulneráveis.

As mudanças legislativas em matéria penal são importantes, mas não são suficientes. É preciso que elas estejam aliadas às políticas públicas efetivas e concatenadas com a realidade, para que desta forma sejam mensurados e percebidos resultados positivos, tanto no combate quanto na coibição da prática do delito de homicídio; especialmente, contra as mulheres que já convivem com um histórico de violência persistente nos lares, nas escolas, no trabalho, na rua, no país e no mundo. 


\section{O CRIME DE HOMÍCIDIO}

Antes de defrontar as questões pertinentes ao feminicídio, mister a contextualização do crime de homicídio, haja vista a sensível interligação entre eles. Dispõe o artigo 121 do vigente Código Penal (Decreto-lei $n^{\circ} 2.848$, de 7 de dezembro de 1940) que o homicídio é o crime de matar alguém, ou seja, corresponde a prática de ceifar a vida de outrem.

O crime de homicídio inaugura a parte especial do Códex Penal, o que demonstra a relevância e o cuidado do legislador com o bem jurídico vida humana. Frisa-se que a vida do ser humano é um direito absoluto com caráter dúplice, pois além de ser um direito público subjetivo, também é um direito privado indisponível.

Não são exigidas qualificações especiais para que o agente ativo - o autor do delito venha a praticar a conduta típica descrita no tipo penal em epígrafe, que é a retirada não natural da vida de outra pessoa.

Embora soe redundante, o sujeito passivo deve ser uma pessoa, sem demais particularidades - ou seja, um ser humano nascido de mulher e com vida ${ }^{3}$. De tal modo que não se pratica homicídio (nomen juris específico) contra animais; in casu, utiliza-se a denominação geral criminoso.

Portanto, o objeto material do delito é o ser humano com vida ${ }^{4}$, tendo como elemento subjetivo o dolo ${ }^{5}$, que corresponde ao animus necandi de ceifar a vida de outrem, com a possibilidade de ser praticado também de forma culposa ${ }^{6}$. Ademais, a consumação é verificada com a efetiva morte, que se dá com a constatação da ausência de sinais vitais na vítima.

Em síntese, consoante a doutrina penal, o crime de homicídio pode ter as seguintes classificações, dependendo do caso concreto: crime comum tanto para o sujeito ativo quanto passivo; via de regra é de forma livre; pode ser praticado dolosa ou culposamente e comissiva

\footnotetext{
${ }^{3}$ No caso dos fetos que ainda estão com vida intrauterina e que venham a ter sua vida interrompida, será aplicado ao agente ativo as sanções dispostas nos artigos 124 a 128 do Código Penal, correspondente ao crime de aborto, salvo se feto anencefálico. Isso porque, ao feto anencefálico o aborto poderá ser praticado com respaldo legal, desde que nos moldes da decisão do Supremo Tribunal Federal (STF) na ADPF - Arguição de Descumprimento de Preceito Fundamental no 54, julgada em 2012.

${ }^{4}$ Além de ser um crime impossível matar alguém que já não possua quaisquer indicativos de vida, eventual violência causada contra o cadáver se enquadrará nas condutas tipificadas nos artigos 211 ou 212 do Código Penal, que preconizam a destruição, subtração ou ocultação de cadáver e vilipêndio à cadáver, respectivamente.

${ }^{5}$ Bitencourt (2016, p. 63) explica que considerando que o dolo prescinde de dois elementos, quais sejam o cognitivo (conhecimento da tipicidade da conduta) e o volitivo (vontade do agente de realizar a conduta), o crime em epígrafe está relacionado com o dolo de dano e não de perigo, haja vista a exigência de que o agente ativo possua a real intenção de produzir o dano contra o bem jurídico tutelado.

${ }^{6}$ Conforme o artigo $121, \S 3^{\circ}$ do Código Penal o crime de homicídio pode ser praticado de forma culposa e com diferentes causas de aumento de pena, conforme os $\S \S 4^{\circ}$ a $6^{\circ}$ do mesmo artigo.
} 
ou omissivamente; de dano; material; instantâneo de efeitos permanentes; não transeunte; monossubjetivo; plurissubisistente; admite tentativa e comporta a hipótese de crime de ímpeto ${ }^{7}$.

O crime de homicídio abrange as modalidades: (a) simples, que é a prática de matar alguém, com pena de reclusão de 6 (seis) a 20 (vinte) anos (artigo 121, caput do Código Penal); (b) privilegiada, que incide uma causa especial de redução de pena, de 1/6 (um sexto) a 1/3 (um terço), (artigo 121, $\S 1^{\circ}$ do Código Penal); (c) qualificada.

Quando o crime de homicídio é praticado em circunstâncias socialmente mais reprováveis, ele se enquadrará na modalidade qualificada, que resultará em uma pena mais severa ao agente, correspondente à reclusão de 12 (doze) a 30 (trinta) anos (artigo 121, §2 ${ }^{\circ}$ do Código Penal).

Importante ressaltar que as elementares do tipo e as circunstâncias do delito não são sinônimas. As primeiras são os elementos típicos ou essenciais que integram a definição do delito, de tal modo que a ausência de um dos elementos descritos no delito sob análise poderá descaracterizar o crime, seja para outro crime, para uma contravenção penal ou mesmo descriminaliza a conduta.

Por sua vez, a segunda refere-se aos elementos acessórios ou incidentais que influem na mensuração da gravidade do crime (quantis delicti), tendo em vista que as circunstâncias poderão aumentar ou diminuir a pena-base do criminoso.

O crime de homicídio qualificado é um crime hediondo e, portanto, ele é inafiançável e insuscetível de graça, anistia ou indulto, conforme os artigos $1^{\circ}$, inciso I; artigo $2^{\circ}$, inciso I e II da Lei $n^{\circ} 8.072 / 90$ e artigo $5^{\circ}$, inciso XLIII da Constituição da República Federativa do Brasil de 1988.

Ao todo o crime de homicídio comporta 7 (sete) qualificadoras, conforme os incisos do artigo 121, §2 do Código Penal, classificadas doutrinariamente como objetivas (também denominadas como materiais ou reais) e subjetivas (ou pessoais).

Artigo 121, $\S 2^{\circ}$ : I - mediante paga ou promessa de recompensa, ou por outro motivo torpe; II - por motivo fútil; III - com emprego de veneno, fogo, explosivo, asfixia, tortura ou outro meio insidioso ou cruel, ou de que possa resultar perigo comum; IV - à traição, de emboscada, ou mediante dissimulação ou outro recurso que dificulte ou torne impossível a defesa do ofendido; V - para assegurar a execução, a ocultação, a impunidade ou vantagem de outro crime; VI - contra a mulher por razões da condição de sexo feminino; VII - contra autoridade ou agente

\footnotetext{
${ }^{7}$ Quando o agente realiza o crime impelido por causa de violenta emoção, logo após injusta provocação da vítima.
} 
descrito nos arts. 142 e 144 da Constituição Federal, integrantes do sistema prisional e da Força Nacional de Segurança Pública, no exercício da função ou em decorrência dela, ou contra seu cônjuge, companheiro ou parente consanguíneo até terceiro grau, em razão dessa condição. (CÓDIGO PENAL, 1940)

Serão classificadas como circunstâncias objetivas quando elas tiverem ligação com os meios e modos de execução do crime. Por sua vez serão qualificadoras subjetivas aquelas atinentes com os motivos determinantes do delito (condição e qualidades pessoais do autor ou da vítima, por exemplo); logo, elas não estarão relacionadas com a materialidade do delito.

Haja vista os perseverantes índices de violência e homicídios contra as mulheres no Brasil, o Poder Público resolveu potencializar a penalização dos homicidas motivados pela vulnerabilidade do gênero feminino, criando a qualificadora do feminicídio, que será abordada a seguir.

\section{O FEMINICÍDIO NO BRASIL}

Como a violência é uma ocorrência típica do cotidiano do ser humano em todo o período de formação e manutenção da civilização, e que o crime de homicídio é o ápice desta violência, destaca-se que em relação as mulheres essas situações de selvageria se perpetuam no decorrer da história.

No Brasil, os relatos de violência contra as mulheres percorrem a história e a partir do momento em que iniciaram as pesquisas acerca deste tipo de violência - que até então era considerado arcaicamente uma circunstância familiar e provocada exclusivamente pela mulher -, foi evidenciada a seriedade do problema.

[Conforme pesquisa realizada no ano de 2014 no Brasil], a violência física [contra a mulher] é, de longe, a mais frequente, presente em 48,7\% dos atendimentos [pelo SUS - Sistema Único de Saúde] com especial incidência nas etapas jovem e adulta da vida da mulher, quando chega a representar perto de $60 \%$ do total de atendimentos. Em segundo lugar, a violência psicológica, presente em 23,0\% dos atendimentos em todas as etapas, principalmente da jovem em diante. Em terceiro lugar, a violência sexual, objeto de 11,9\% dos atendimentos, com maior incidência entre as crianças até 11 anos de idade $(29,0 \%$ dos atendimentos) e as adolescentes $(24,3 \%)$. (WAISELFISZ, 2015, p. 52)

A título de ilustração da segregação das mulheres em solo pátrio, tem-se o fato do Código Penal de 1890 ter tido disposições degradantes e discriminatórias contra a mulher, como o conceito de mulher honesta; o direito ao voto feminino ter sido apenas conquistado 
em 1932; a violência doméstica e familiar, frisa-se, ser considerada uma circunstância de âmbito privado, sem necessidade de intervenção estatal.

Dentre os inúmeros tratados ratificados pelo Brasil sobre Direitos Humanos, está a Convenção sobre a Eliminação de Todas as Formas de Discriminação Contra a Mulher de 1979, promulgada pelo Decreto $\mathrm{n}^{\mathrm{o}} 4.377$, de 13 de setembro de 2002, dispondo no artigo $2^{\circ}$

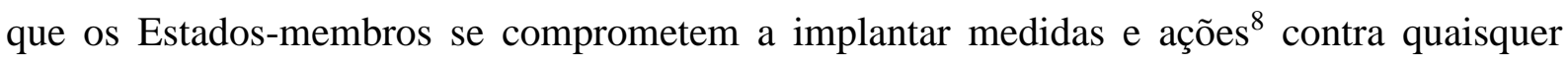
formas de discriminação negativa à mulher.

Artigo $1^{\circ}$. Para os fins da presente Convenção, a expressão "discriminação contra a mulher" significará toda a distinção, exclusão ou restrição baseada no sexo e que tenha por objeto ou resultado prejudicar ou anular o reconhecimento, gozo ou exercício pela mulher, independentemente de seu estado civil, com base na igualdade do homem e da mulher, dos direitos humanos e liberdades fundamentais nos campos político, econômico, social, cultural e civil ou em qualquer outro campo. (Decreto $\mathrm{n}^{\circ} 4.377 / 2002$ )

Todavia, as mudanças estatais foram de plano meramente formais e diminutas em comparação ao enraizamento cultural da violência contra a mulher em solo pátrio. Mesmo com a realização da Convenção Interamericana para Prevenir, Punir e Erradicar a Violência Contra a Mulher (Convenção de Belém do Pará), que em 1994 determinou vários compromissos para melhorar a situação, a efetividade do documento igualmente demostrou poucos resultados.

Tal afirmação é corroborada pelo relatório da Comissão Interamericana de Direitos Humanos, que concluiu em 2001 que o Brasil foi negligente no caso da brasileira Maria da Penha Maia Fernandes, que embora tenha sofrido inúmeras violências físicas e tentativas de homicídio pelo seu cônjuge, o julgamento do seu agressor foi postergado e a condenação ínfima.

\footnotetext{
${ }^{8} \mathrm{O}$ artigo $2^{\circ}$ dispõe que "Os Estados Partes condenam a discriminação contra a mulher em todas as suas formas, concordam em seguir, por todos os meios apropriados e sem dilações, uma política destinada a eliminar a discriminação contra a mulher, e com tal objetivo se comprometem a: a) Consagrar, se ainda não o tiverem feito, em suas constituições nacionais ou em outra legislação apropriada o princípio da igualdade do homem e da mulher e assegurar por lei outros meios apropriados a realização prática desse princípio; b) Adotar medidas adequadas, legislativas e de outro caráter, com as sanções cabíveis e que proíbam toda discriminação contra a mulher; c) Estabelecer a proteção jurídica dos direitos da mulher numa base de igualdade com os do homem e garantir, por meio dos tribunais nacionais competentes e de outras instituições públicas, a proteção efetiva da mulher contra todo ato de discriminação; d) Abster-se de incorrer em todo ato ou prática de discriminação contra a mulher e zelar para que as autoridades e instituições públicas atuem em conformidade com esta obrigação; e) Tomar as medidas apropriadas para eliminar a discriminação contra a mulher praticada por qualquer pessoa, organização ou empresa; f) Adotar todas as medidas adequadas, inclusive de caráter legislativo, para modificar ou derrogar leis, regulamentos, usos e práticas que constituam discriminação contra a mulher; g) Derrogar todas as disposições penais nacionais que constituam discriminação contra a mulher. " (CONVENÇÃO SOBRE A ELIMINAÇÃO DE TODAS AS FORMAS DE DISCRIMINAÇÃO CONTRA A MULHE, 1979)
} 
A inferiorização cultural da mulher também é um traço presente na atual sociedade brasileira, corroborada com a atuação negligente e imprudente do Estado, que ao invés de diminuir a tensão existente entre os gêneros a reforça, como ocorre no sistema de justiça criminal (vide o julgamento do caso Maria da Penha, por exemplo).

Isso porque observa-se as mesmas máculas nos julgamentos realizados nos Tribunais do Júri espalhados pelo país, em que predomina o pensamento e atitudes machistas nos casos de homicídio (ou tentativa) contra as mulheres, dado o uso de argumentos eivados de neutralização da violência praticada contra elas e inclusive de culpabilização da mulher por estar neste contexto de hostilidade. (CARVALHO; ROSA, 2016, p. 180)

Conquanto verifiquem-se alguns avanços, principalmente com os movimentos feministas, reforça-se que ainda vigora valores estereotipados, machistas, preconceituosos e discriminadores, que subjugam a mulher e banalizam a violência doméstica e familiar ${ }^{9}$.

Corroboram com a assertiva o fato de que em 2013 foram registrados pelo Sistema de Informações de Mortalidade (SIM) o total de 4.762 homicídios de mulheres, sendo que $50,3 \%$ deste total (ou seja, 2.394) foram realizados por algum familiar da vítima. "Isso representa perto de 7 feminicídios diários nesse ano, cujo autor foi um familiar. 1.583 dessas mulheres foram mortas pelo parceiro ou ex-parceiro, o que representa $33,2 \%$ do total de homicídios femininos nesse ano. "(WAISELFISZ, 2015, p. 70)

Além das cicatrizes e marcas físicas causadas pelo crime de violência doméstica e familiar causadas contra as mulheres, há também as chagas psicológicas e o ultraje a própria dignidade da mulher, pois ela tem desrespeitada a sua condição de cidadã e os seus direitos mínimos como ser humana, seja na fase da infância, adolescência, adulta e até mesmo idosa.

\footnotetext{
${ }^{9}$ Apenas denota-se uma pequena mudança estatal e cultural com a edição da Lei Maria da Penha (Lei ${ }^{\circ}$ 11.340/2006).

Dispõe o artigo $7^{\circ}$ da Lei no 11.340/2006 que: "São formas de violência doméstica e familiar contra a mulher, entre outras: I - a violência física, entendida como qualquer conduta que ofenda sua integridade ou saúde corporal; II - a violência psicológica, entendida como qualquer conduta que lhe cause dano emocional e diminuição da autoestima ou que lhe prejudique e perturbe o pleno desenvolvimento ou que vise degradar ou controlar suas ações, comportamentos, crenças e decisões, mediante ameaça, constrangimento, humilhação, manipulação, isolamento, vigilância constante, perseguição contumaz, insulto, chantagem, ridicularização, exploração e limitação do direito de ir e vir ou qualquer outro meio que lhe cause prejuízo à saúde psicológica e à autodeterminação; III - a violência sexual, entendida como qualquer conduta que a constranja a presenciar, a manter ou a participar de relação sexual não desejada, mediante intimidação, ameaça, coação ou uso da força; que a induza a comercializar ou a utilizar, de qualquer modo, a sua sexualidade, que a impeça de usar qualquer método contraceptivo ou que a force ao matrimônio, à gravidez, ao aborto ou à prostituição, mediante coação, chantagem, suborno ou manipulação; ou que limite ou anule o exercício de seus direitos sexuais e reprodutivos; IV - a violência patrimonial, entendida como qualquer conduta que configure retenção, subtração, destruição parcial ou total de seus objetos, instrumentos de trabalho, documentos pessoais, bens, valores e direitos ou recursos econômicos, incluindo os destinados a satisfazer suas necessidades; V - a violência moral, entendida como qualquer conduta que configure calúnia, difamação ou injúria. "
} 
[Em 2014 o SUS - Sistema único de Saúde constatou que] 82\% das agressões a crianças do sexo feminino, de $<1$ a 11 anos de idade, que demandaram atendimento pelo SUS, partiram dos pais - principalmente da mãe, que concentra $42,4 \%$ das agressões. Para as adolescentes, de 12 a 17 anos de idade, o peso das agressões divide-se entre os pais $(26,5 \%)$ e os parceiros ou ex-parceiros $(23,2 \%)$. Para as jovens e as adultas, de 18 a 59 anos de idade, o agressor principal é o parceiro ou exparceiro, concentrando a metade do todos os casos registrados. Já para as idosas, o principal agressor foi um filho $(34,9 \%)$. No conjunto de todas as faixas, vemos que prepondera largamente a violência doméstica. Parentes imediatos ou parceiros e exparceiros (...) são responsáveis por $67,2 \%$ do total de atendimentos. (WAISELFISZ, 2015, p. 48)

Urge destacar que a "cada dia de 2014, 405 mulheres demandaram atendimento em uma unidade de saúde, por alguma violência sofrida" (WAISELFISZ, 2015, p. 29 e 42) e em 2013 o Brasil ocupou a quinta posição no ranking mundial dos países com mais ocorrências de feminicídio, com o registro de 4,8 homicídios de mulheres por 100 mil brasileiras.

O "Atlas da Violência 2017" constatou que embora a taxa de homicídio de mulheres entre 2005 e 2015 tenha elevado para 7,5\%, verifica-se que nos anos mais recentes houve uma "melhora gradual", haja vista a diminuição de 2,8\% na taxa entre 2010 e 2015, e a queda de 5,3\% apenas no último ano da série. (CERQUEIRA et. al, 2017, p. 36) Todavia, tais números são diminutos em relação a magnitude do problema e a necessidade premente de efetivação do direito e garantia fundamental da dignidade da mulher e respeito ao seu gênero pela sociedade contemporânea brasileira.

Ademais, o panorama de violência contra a brasileira foi inexpressivamente modificado em 2015 em comparação ao ano anterior. Em verdade, não se deve nem mesmo considerar que houve alguma mudança, dada a constatação de que em 20144.621 mulheres foram assassinadas em território nacional, alcançando a taxa de 4,5 mortes para cada 100 mil mulheres. (CERQUEIRA et. al, 2017, p. 36)

A violência contra a mulher não se limita a idade, a classe social e/ou ao grau de instrução que a vítima possui, pois ela é evidenciada independente do status social. Entretanto, indubitável o fato da violência ser mais corriqueira com as mulheres mais pobres.

É digno de nota o fato de que o silêncio das vítimas, familiares, amigos, vizinhos ou de outras pessoas que tenham ciência da situação de violência é um dos instrumentos favorecedores para a perpetuação e banalização desta selvageria nos lares, ruas, shows, escolas, centros religiosos, entre outras localidades, tanto no país quanto fora dele. 
Outro ponto de extrema gravidade relacionado com a violência contra as brasileiras é o fato das mulheres afrodescentes serem as maiores vítimas de mortes por agressão em comparação com as mulheres não afrodescentes.

Enquanto a mortalidade de mulheres não negras teve uma redução de $7,4 \%$ entre 2005 e 2015, atingindo 3,1 mortes para cada 100 mil mulheres não negras - ou seja, abaixo da média nacional -, a mortalidade de mulheres negras observou um aumento de $22 \%$ no mesmo período, chegando à taxa de 5,2 mortes para cada 100 mil mulheres negras, acima da média nacional. (CERQUEIRA et. al, 2017, p. 37)

Alarmantemente $65,3 \%$ das brasileiras assassinadas em 2015 eram afrodescentes ${ }^{10}$, de tal modo que restou ainda mais evidenciado no Atlas da Violência 2017 de que "a combinação entre desigualdade de gênero e racismo é extremamente perversa e configura variável fundamental para compreendermos a violência letal contra a mulher no país". (CERQUEIRA et. al, 2017, p. 37)

Considerando que "a violência física doméstica é cotidiana, rotineira e rotinizada, e geralmente produtora de uma escalada, em que a morte pode vir a ser (mas nem sempre é) o ponto final. A morte é sempre o significante evocado através da constância das ameaças" (MACHADO, 1998, p. 6), foram feitas alterações na legislação penal.

O crime de homicídio praticado contra a mulher no âmbito da violência doméstica e familiar, via de regra, era qualificado pela torpeza; contudo, com a promulgação da Lei $n^{\circ}$ 13.104 no ano de 2015, foi inclusa a qualificadora do feminicídio ao Códex Penal (artigo 121, $\S 2^{\circ}$, inciso VI e $\left.\S 2^{\circ}-A, \S 7^{\circ}\right)$.

Rubim e Marques (2016, p. 233) acrescentam que a Lei ${ }^{\circ} 13.104 / 2015$ teve como objetivo tornar a punição do crime de feminicídio mais grave a fim de reprimir a sua ocorrência e, por conseguinte, intimidar os agressores por meio do caráter punitivo, educativo e preventivo da pena.

E embora a qualificadora do feminicídio possa parecer redundante, dado que o legislador infraconstitucional mantém a lógica da penalização qualificada do crime de homicídio praticado contra a mulher por causa do gênero, os intentos com a edição da Lei ultrapassam a análise da aplicação da pena, pois visam enfatizar a necessidade de prevenir e combater esse crime que possui alarmantes índices no Brasil.

\footnotetext{
10 “As maiores taxas de letalidade entre mulheres negras foram verificadas no Espírito Santo $(9,2)$, Goiás $(8,7)$, Mato Grosso $(8,4)$ e Rondônia $(8,2)$. Apenas sete Unidades da Federação lograram redução na taxa de mortalidade de mulheres negras por homicídio entre 2005 e 2015, sendo eles: São Paulo (-41,3\%); Rio de Janeiro (-32,7\%); Pernambuco (-25,8\%); Paraná (-23,9\%); Amapá (-20\%); Roraima (-16,6\%); e Mato Grosso do Sul (-4,6\%).” (CERQUEIRA et. al, 2017, p. 37)
} 
A expressão femicídio é atribuída à Diana Russel ${ }^{11}$, que a utilizou em 1976 durante um depoimento no Tribunal Internacional de Crimes contra mulheres, em Bruxelas. Posteriormente, ela escreveu em coautoria com Jill Radford a importante obra Femicide: The politics of woman killing (1992).

Femicide has many different forms: for exemple, racist femicide (when black women are killed by white men); homophobic femicide, or lesbicide, (when lesbians are killed by heterosexual men); marital femicide (when women are killed by their husbands); femicide commited outside the home by a stranger; serial femicide; and mass femicide. In this era of AIDS, femicide includes the deliberate of the HIV virus by rapists. The concept of femicide also extends itself beyond legal definitions of murder to include situations in which women are permited to die as a result of misogynous attitudes or social pratices. ${ }^{12}$ (RUSSEL; RADFORD, 1992, p. 7)

Do termo femicídio derivou o feminicídio, criado pela mexicana Marcela Lagarde. Sintetiza Campos (2015, p. 106) que segundo Lagarde o feminicídio é um crime de Estado, pois está atrelado a ocorrência das situações de impunidade, omissão, negligência e conveniência pelas autoridades competentes na apuração dos crimes contra as mulheres e, por conseguinte, deixam esta parcela da população sem segurança.

Embora as expressões femicídio e feminicídio possuam algumas diferenças ${ }^{13}$ conceituais calcadas na historicidade com que elas surgiram, a essência é muito parecida, sendo corriqueiro o uso delas como sinônimas.

[As] condutas pelas quais as feministas identificam o femicídio/feminicídio revelam as características específicas dessas mortes, isto é, a sua conformação diferenciada do homicídio. Por exemplo, a existência de violência sexual, mutilação e desfiguração do corpo da vítima (especialmente seios, vagina e rosto) desvelam um comportamento misógino ${ }^{14}$. A morte nas (ex)relações íntimas de afeto demonstra não apenas a vulnerabilidade das mulheres no interior dessas relações, mas a tentativa de controle e posse absolutas sobre o corpo feminino que não pode ser entendida como comportamentos motivados por ciúme ou violenta emoção. Em geral, são crimes premeditados, originados do machismo culturalmente enraizado na

\footnotetext{
${ }^{11}$ Diana Russel explica no prefácio do livro Femicide: The politics of woman killing (1992), que a primeira vez que tomou conhecimento do termo femicídio foi em 1975 através de uma conhecida que comentou acerca de uma antologia (coletânea) sobre o femicídio que estava sendo desenvolvida pela americana Carol Orlock. Logo, Diana Russel não é a criadora do termo, mas sim a propulsora.

12 "O femicídio tem muitas formas diferentes: por exemplo, femicídio racista (quando mulheres negras são mortas por homens brancos); Femicídio homofóbico, ou de lésbicas, (quando as lésbicas são mortas por homens heterossexuais); Femicídio conjugal (quando mulheres são mortas por seus maridos); femicídio cometido fora de casa por um estranho; femicídio serial; e femicídio em massa. Nesta era da AIDS, o femicídio inclui a deliberação do vírus HIV pelos estupradores. O conceito de femicídio também se estende além das definições legais de assassinato para incluir situações em que as mulheres são permitidas morrer em consequência de atitudes misóginas ou práticas sociais. " (Tradução nossa)

${ }^{13}$ Em apertada síntese, o femicídio abarcaria a morte de mulher e o feminicídio a morte de mulher por causa do gênero.

${ }^{14}$ Misoginia corresponde ao sentimento de repulsa ou aversão às mulheres.
} 
sociedade. Não há perda do controle ou injusta provocação da vítima, mas uma atitude consciente de negação do direito à autonomia feminina. O reconhecimento da violenta emoção nesses casos configura tolerância estatal a crimes machistas e sexistas, pois não pode haver violenta emoção quando a motivação é impedir a autodeterminação feminina, conduta tão bem expressa na frase "se não for minha não será de ninguém”. (CAMPOS, 2015, p. 109)

O feminicídio, portanto, pode ser conceituado como o homicídio doloso praticado contra a mulher por razões da condição de sexo feminino, ou seja, é um delito praticado balizado em sentimentos e preconceitos machistas arcaicos e discriminadores que consideram as pessoas do sexo feminino, que estejam ou não no contexto familiar ${ }^{15}$, inferiores e com menos direitos que os homens.

Utilizando a classificação da mexicana Julia Estela Fragoso Monárrez sobre feminicídio, ela explica que o termo abrange 4 (quatro) tipos, quais sejam: (a) o sexual, (b) o sexista, (c) por narcotráfico e (d) por adição ${ }^{16}$. Rubim e Marques (2016, p. 299) concluíram que no Brasil o tipo mais corriqueiro é o sexista. Ele ocorre quando se matam mulheres pelo desejo de demonstrar o poder (domínio e controle) sobre elas. Por isso é muito comum que ele ocorra quando o agente possui ciúmes da vítima - situação em que ele está investido do sentimento de posse -, com o emprego de armas de fogo e brancas, incineração e violência física. Ou seja, os agentes preferem usar os métodos mais cruéis e que causam maior sofrimento à vítima.

Considerando os dados apresentados pelo "Mapa da violência 2015: Homicídio de mulheres no Brasil”, a legislação pertinente à qualificadora e às pesquisas científicas relacionadas com o feminicídio, compactua-se com a conclusão supra.

Seguindo, esta qualificadora subjetiva incide quando a motivação do agente para a prática do homicídio contra a mulher é a condição do sexo feminino, nas circunstâncias de violência doméstica e familiar (artigo 121, $\$ 2^{\circ}$-A, inciso I do Código Penal), ou por

\footnotetext{
${ }^{15}$ Importante ressalvar que o feminicídio praticado em um relacionamento homoafetivo entre duas mulheres, via de regra, a inferiorização de uma parceria pela outra decorre do contexto familiar e não pela condição do sexo feminino.

16 Sintetizando a classificação de MONÁRREZ acerca do feminicídio, Rubim e Marques (2016, p. 229) verificaram que "a) os sexuais, [estão] associados ao desejo explícito de matar uma mulher pela questão de gênero, a exemplo dos serial killers, quando escolhem as mulheres como vítima. Normalmente esses algozes matam suas vítimas com vários golpes, práticas de torturas, estrangulamento, incineração, entre outros atos cruéis. (...) [Será] c) por narcotráfico quando a morte de mulheres se dá no contexto do tráfico de drogas no qual elas concorrem com homens pelo espaço no mercado dos entorpecentes ou quando estão sem a proteção do parceiro que é envolvido no ramo do tráfico de drogas. Nestes casos as mulheres costumam ser mortas com armas de fogo ou presas no cárcere. [E será] d) por adição, quando a morte de mulheres se dá em decorrência do consumo exacerbado de álcool e ao uso de entorpecentes, geralmente associado ao fato de estarem à margem da sociedade. Estas vítimas muitas vezes são exploradas, abusadas sexualmente em troca da manutenção do vício, e posteriormente mortas."
} 
menosprezo ou discriminação à condição de mulher (artigo 121, §2º-A, inciso II do Código Penal).

Destarte, por ser uma qualificadora vinculada ao caráter pessoal e que incide sobre a culpabilidade, ela apenas será aplicada ao autor que comprovadamente estava estimulado por causa do gênero feminino para cometer o delito, de tal modo que os coautores não serão abarcados pela qualificadora (salvo se evidenciada a mesma motivação do autor).

Greco (2016, p. 41) ressalta que o agente ativo tanto pode ser homem quanto mulher, pois mesmo em uma relação homoafetiva feminina, em que uma das parceiras cause a morte da companheira num contexto de unidade doméstica, também poderá ser aplicada a qualificadora do feminicídio.

Dentre os critérios doutrinários para a definição penal do que é ser mulher, filia-se ao entendimento de Cunha (2016) que adota o critério jurídico, pois o biológico desconsidera o transexual (aquele que realizou procedimento cirúrgico para a mudança de sexo) e o psicológico (por exemplo, o travesti que obteve o reconhecimento formal de sua opção sexual).

Em relação as hipóteses de ocorrência do crime em razão do sexo feminino, considera-se âmbito familiar a comunidade de pessoas unidas por um vínculo jurídico civil, seja ele familiar, conjugal, por parentesco ou vontade expressa, com uma relação íntima de afeto.

E unidade doméstica o local onde um grupo de pessoas convivem com animus domicili ou esporadicamente, sem vínculo familiar. Em 2013, 27,1\% dos homicídios contra as mulheres ocorreram no domicilio da vítima, 31,2\% na rua, e em 48,8\% dos casos foi empregada arma de fogo. (WAISELFISZ, 2015, p. 41 e 50)

Frisa-se que mesmo que a violência tenha sido praticada em local diverso da residência comum entre a vítima e o agressor, se restar comprovada a existência de lações familiares entre eles, a violência contra a mulher estará caracterizada. (LIMA, 2016, p. 906) Logo, a coabitação não é uma elementar do crime de feminicídio.

Para compreensão da expressão menosprezo ou discriminação contra a mulher, utiliza-se a Convenção sobre Eliminação de Todas as Formas de Discriminação Contra a Mulher, datada de 1979 e ratificada pelo Brasil em 1984.

Artigo $1^{\circ}$ - Para fins da presente Convenção, a expressão "discriminação contra a mulher" significará toda distinção, exclusão ou restrição baseada no sexo e que tenha por objeto ou resultado prejudicar ou anular o reconhecimento, gozo ou 
exercício pela mulher, independentemente de seu estado civil, com base na igualdade do homem e da mulher, dos direitos humanos e liberdades fundamentais nos campos político, econômico, social, cultural e civil ou em qualquer outro campo. (CONVENÇÃO SOBRE A ELIMINAÇÃO DE TODAS AS FORMAS DE DISCRIMINAÇÃO CONTRA A MULHER, 1979)

O feminicídio será mais severamente punido, com o aumento de pena de 1/3 (um terço) até a metade, se praticado durante a gestação ou nos 3 (três) meses posteriores ao parto, contra pessoa menor de 14 (quatorze) anos, maior de 60 (sessenta) anos ou com deficiência, assim como, se for realizado na presença de descendente ou de ascendente da vítima (artigo $121, \S 7^{\circ}$, incisos I, II e III do Código Penal).

Como o feminicídio é um homicídio qualificado, ele também é considerado um crime hediondo; ademais, não admite a forma privilegiada e conforme a Súmula 542 do Superior Tribunal de Justiça (STJ) é de Ação Penal Pública Incondicionada.

E a alegação de que o feminicídio estaria descumprindo com o princípio constitucional expresso da igualdade não prospera (vide artigo $5^{\circ}$, inciso I). Primeiro porque deve-se atentar ao alcance material deste preceito, que assevera o tratamento igual aos iguais e desigual aos desiguais, estes últimos na medida da desigualdade. Logo, considerando a vulnerabilidade da mulher no contexto de violência afetiva, doméstica e/ou familiar, ou causada pela condição do sexo feminino é motivo suficiente para o tratamento legal diferenciado.

Acompanha esse entendimento Campos (2015, p. 112), o qual acrescenta que não se trata de um tratamento paternalista que considera a mulher um sexo frágil, mas sim porque há a necessidade de qualificar o crime de homicídio contra as mulheres por causa do gênero feminino atribuindo um nomen iuris próprio, com duas circunstâncias específicas, para assim "levantar o véu de uma realidade não nominada" escondida pelas então qualificadoras do crime em comento, supostamente neutras de gênero.

Outrossim na apreciação pelo Supremo Tribunal Federal (STF) da Ação Declaratória de Constitucionalidade (ADC) $\mathrm{n}^{\mathbf{0}} 19$ e da Ação Direta de Inconstitucionalidade (ADI) $\mathrm{n}^{\circ}$ 4424, julgadas em 9 de fevereiro de 2012, em que se aduziam a infringência do preceito igualitário disposto na Constituição pela Lei $n^{\circ}$ 11.301/2006 (Lei Maria da Penha), restou pacificada a constitucionalidade da Lei. Por conseguinte, mesmo entendimento deve ser deferido ao feminicídio.

Dado os números alarmantes evidenciados neste trabalho e a necessidade do robustecimento do ius puniendi contra os homicidas de mulheres, essa máxima da violência 
deve ser extirpada antes mesmo que qualquer fala, olhares, tatos maldosos e cruéis venham a acontecer e sejam tidos como "normais" pela sociedade e pelas próprias vítimas. Explica Russel e Radford:

But killings is just the tip of the iceberg. For every murdered wife, hundreds are beaten, coerced and intimidated. Although homicide probably does not often serve the interests of the perpetrator, it is far from clear that the same can be said of sublethal violence. Men, as we noted earlier, strive to control women, albeit with variable sucess; women struggle to resist coercion and to maintain their choices. There is brinkmanship and risk of disaster in any such contest, and homicides by spouses of either sex may be considered the slips in this dangerous game. ${ }^{17}(1992$, p. 93)

As origens do feminicídio (ou seja, a violência contra à mulher) precisam ser urgentemente combatidas pelo Estado com políticas públicas de conscientização; atendimento particularizados à vítima e à família; tramitação processual escorreita e eficiente e com a efetiva punição do agressor - haja vista que justiça tardia, não é justiça; entre outros. Ademais, a arcaica e inescrupulosa cultura do femicídio precisa acabar.

A femicide culture is one in which the male is worshipped. This worship is obtained through tyranny, subtle and overt, over our bruised minds, our battered and dead bodies, and our co-optation into supporting even batterers, rapists, and killers. "Bassically, I worshipped him," said Hedda Nussbaum. "We do not worship them... we do not trust them," writes Alice Walker. In myriad ways, let us refuse nature, solace, support, and approval. Let us withdraw our worship. ${ }^{18}$ (RUSSEL; RADFORD, 1992, p. 21)

Portanto, a população brasileira também deve mudar a postura a fim de promover o reconhecimento da mulher como pessoa e não como um objeto de deleite do comportamento machista, sendo respeitadas as particularidades do universo mulheril, rompendo com a discriminação do feminino na sociedade, no grupo familiar/doméstico, no trabalho, na escola, na rua e por ela mesma.

\footnotetext{
17 "Mas os assassinatos são apenas a ponta do iceberg. Para cada mulher assassinada, centenas são espancadas, coagidas e intimidadas. Embora o homicídio provavelmente não sirva frequentemente aos interesses do perpetrador, não está claro se o mesmo pode ser dito da violência subletal. Os homens, como observamos anteriormente, procuram controlar as mulheres, embora com sucesso variável; as mulheres lutam para resistir à coerção e para manter suas escolhas. Há uma tática arriscada [brinkmanship] e risco de desastre em qualquer disputa, e homicídios por cônjuges de ambos os sexos podem ser considerado o deslizamento neste jogo perigoso. " (tradução nossa)

18 'Uma cultura femicida é aquela em que o macho é adorado. Essa adoração é obtida através da tirania, sutil e explícita, sobre nossas magoadas mentes, nossos corpos surrados e mortos, e nossa cooptação em apoiar até mesmo agressores, estupradores e assassinos. "Basicamente, eu o adorava", disse Hedda Nussbaum. "Nós não os adoramos ... não confiamos neles", escreve Alice Walker. De inúmeras maneiras, vamos recusar a natureza, consolo, apoio e aprovação. Retiremos nossa adoração. " (Tradução nossa)
} 


\section{CONSIDERAÇÕES FINAIS}

O reconhecimento social, individual, político e jurídico da brasileira teve alguns avanços no Estado contemporâneo, porém a concretude desses direitos e mitigação da segregação entre os gêneros está em um constante e oscilante processo histórico, com involuções na segurança e manutenção da vida da mulher, tanto em ambiente coletivo quanto particular.

A perpetuação e os elevados índices de violência e assassinatos contra as brasileiras por causa do gênero, evidenciada na pesquisa "Mapa da violência 2015: Homicídio de mulheres no Brasil”, denota a omissão estatal em enfrentar pontualmente o problema que se estende pela história do país e o quanto os valores discriminatórios e arcaicos estão enraizados na cultura nacional.

Esses fatores compeliram o Estado a mudar sua postura (até então predominantemente passiva) acerca do homicídio contra as mulheres. Por consequência, foi promulgada a Lei $\mathrm{n}^{\mathrm{o}} 13.104 / 2015$ que incorpora a este delito a qualificadora do feminicídio (artigo 121, $\S 2^{\circ}$, inciso VI e $\S 2^{\circ}$-A, $\S 7^{\circ}$ do Código Penal), para tornar mais severa a punição desta modalidade de crime.

Destarte, quando a motivação do agente para matar uma mulher for decorrente da violência doméstica ou familiar, ou mesmo, for por menosprezo ou discriminação da condição de ser mulher, ele será punido com a pena de reclusão de 12 (doze) a 30 (trinta) anos, e inclusive suportará as demais implicações dos crimes considerados como hediondos.

Outrossim, se o feminicídio for praticado em consonância com alguma das hipóteses do artigo 121, $\S 7^{\circ}$, incisos I, II e III do Código Penal, ao agente também poderá incidir as causas de aumento de pena, dada a maior reprovabilidade da conduta.

Não obstante a Lei Penal ter sido readequada ao contexto social, para que a mudança surta verdadeiros efeitos e esses índices alarmantes de feminicídio diminuam no Brasil, são igualmente necessárias outras medidas estatais interventivas, sendo particularmente deferida uma maior atenção as mulheres pobres e afrodescendentes, tendo em vista estarem mais propensas aos episódios de violência.

Ressalta-se a criação e implementação de políticas públicas adequadas ao combate à violência contra a mulher no grupo familiar, nas relações de afeto e profissionais, com campanhas conscientizadoras; tramitação processual criminal célere, com a punição hábil do 
agressor/homicida; atendimento jurídico, médico, psicológico e assistencial concreto às vítimas; entre outros.

E, enfim, o cenário atual prescinde de uma progressiva evolução cultural para o reconhecimento da mulher, tanto como pessoa quanto como cidadã, pela sociedade em âmbito nacional e internacional, para que realmente as brasileiras possam ter garantida e respeitada a igualdade de condições políticas e sociais para viver.

\section{REFERÊNCIAS}

BRASIL. Decreto-lei no 2.848, de 7 de dezembro de 1940. Código Penal. Disponível em: <http://www.planalto.gov.br/ccivil_03/decreto-lei/Del2848.htm>. Acesso em: 20 jun. 2017.

(a). Lei $\mathrm{n}^{\circ} 11.340$, de 7 de agosto de 2006. Lei Maria da Penha. Disponível em: <http://www.planalto.gov.br/ccivil_03/_ato2004-2006/2006/lei/111340.htm>. Acesso em: 20 jun. 2017.

(b). Decreto $\mathrm{n}^{\circ} 4.377$, de 13 de setembro de 2002. Promulga a Convenção sobre a Eliminação de Todas as Formas de Discriminação contra a Mulher, de 1979, e revoga o Decreto no 89.460, de 20 de março de 1984. Disponível em: <http://www.planalto.gov.br/ccivil_03/decreto/2002/D4377.htm>. Acesso em: 10 jul. 2017.

(c). Constituição da República Federativa do Brasil, 1988. Disponível em: <http://www.planalto.gov.br/ccivil_03/constituicao/constituicao.htm>. Acesso em: 10 jul. 2017.

BITENCOURT, Cezar Roberto. Tratado de Direito Penal: parte especial: crimes contra a pessoa. v. 2. 16. ed. São Paulo: Saraiva, 2016.

Saraiva, 2016.

(a), Cezar Roberto. Tratado de Direito Penal: parte geral. v. 1. 16. ed. São Paulo:

CAMPOS, Carmen Hein de. Feminicídio no Brasil: Uma análise crítico-feminista. Sistema Penal \& Violência, Porto Alegre, v. 7, n. 1, p.103-115, jan/jun. 2015. Semestral. Disponível em:

<http://revistaseletronicas.pucrs.br/ojs/index.php/sistemapenaleviolencia/article/viewFile/202 75/13455>. Acesso em: 10 jul. 2017.

CARVALHO, Gisele Mendes de; ROSA, Gerson Faustino. Feminicídio pra quê? Uma análise dogmática e político-criminal da nova qualificadora do homicídio introduzida pela Lei $\mathrm{n}^{\circ}$ 13.104/2015. CONPEDI: Criminologias e política criminal II, Florianópolis, p.177-197, dez. 2016. Semestral. Disponível em:

<http://www.conpedi.org.br/publicacoes/02q8agmu/ct17i523/ZY19tO1K1Z781JzN.pdf>. Acesso em: 09 jun. 2017. 
CAVALCANTE, Márcio André Lopes. Comentários ao tipo penal do feminicídio (art. 121, § $2^{\circ}$, VI, do CP). In: Dizer o Direito, 11 mar. 2015. Disponível em:

<http://www.dizerodireito.com.br/2015/03/comentarios-ao-tipo-penal-do.html>. Acesso em: 19 jun. 2017.

CERQUEIRA, Daniel; LIMA, Renato Sergio de; BUENO, Samira; VALENCIA, Luis Iván; HANASHIRO, Olaya; MACHADO, Pedro Henrique G.; LIMA, Adriana dos Santos. Atlas da Violência 2017. Rio de Janeiro: IPEA - Instituto de Pesquisa Econômica e Aplicada; FBSP Fórum Brasileiro de Segurança Pública, jun. 2017. Disponível em:

<https://drive.google.com/file/d/0BzuqMfbpwX4wOGQtTmp1SWdXWmM/view>. Acesso em: $01^{\circ}$ ago. 2017.

CONVENÇÃO SOBRE A ELIMINAÇÃO DE TODAS AS FORMAS DE

DISCRIMINAÇÃO CONTRA A MULHER (1979). Disponível em:

<http://www.pge.sp.gov.br/centrodeestudos/bibliotecavirtual/instrumentos/discrimulher.htm>. Acesso em: 13 jun. 2017.

CUNHA, Rogério Sanches. Manual de Direito Penal: Parte Especial (arts. 121 ao 361). 8. ed. Salvador: Jus Podivm, 2016.

GRECO, Rogério. Curso de Direito Penal: parte especial. v. 2. 13. ed. Niterói: Impetus, 2016.

LIMA, Renato Brasileiro de. Legislação Criminal Especial Comentada. 4. ed. Salvador: Jus Podivm, 2016.

MACHADO, Lia Zanotta. Matar e morrer no feminino e no masculino. Brasília:

Departamento de Antropologia da UnB (Universidade de Brasília), 1998. (Antropologia).

Disponível em: <http://www.dan.unb.br/images/doc/Serie239empdf.pdf〉. Acesso em: 18 jun. 2017.

RUBIM, Goreth Campos; MARQUES, Dorli João Carlos. A nova qualificadora do crime de homicídio: O feminicídio. Revista de Gênero, Sexualidade e Direito, Minas Gerais, v. 2, n. 1, p.227-242, jan/jun. 2016. Semestral. Disponível em:

<http://indexlaw.org/index.php/revistagsd/article/view/1124/1117>. Acesso em: 10 jul. 2017.

RUSSELL, Diana E. H.; RADFORD, Jill. Femicide: the politics os woman killing. Twayne Publisher: New York, 1992.

SILVA, Sérgio Gomes da. Preconceito e Discriminação: As Bases da Violência Contra a Mulher. Psicologia, Ciência e Profissão, Brasília, v. 3, n. 30, p.556-571, set/dez. 2010. Quadrimestral. Disponível em: <http://www.redalyc.org/articulo.oa?id=282021784009>. Acesso em: 12 jun. 2017.

WAISELFISZ, Julio Jacobo. Mapa da violência 2015: Homicídio de mulheres no Brasil. 1. ed. Brasília, 2015. Disponível em:

<http://www.mapadaviolencia.org.br/pdf2015/MapaViolencia_2015_mulheres.pdf >. Acesso em: 14 jul. 2017. 